\title{
A foreign body in the recto sigmoid region resulting in colonic perforation and concurrent acute appendicitis
}

\author{
R. Gupta ${ }^{1}$, T.A. Mala ${ }^{1}$, A. Gupta ${ }^{1}$, A.K. Gupta ${ }^{1}$, S.A. Malla ${ }^{2}$, R. Paul ${ }^{3}$ \\ 1 Department of Paediatric Surgery, SPMCHI, SMS Hospital, Jaipur Rajasthan, India. \\ 2 S.S Medical College, Rewa (M.P) India. \\ 3 Jaipur Rajasthan, India.
}

Keywords: Foreign body; recto sigmoid; pen, perforation; acute appendicitis.

\begin{abstract}
A child with a foreign body lodged in the rectoaigmoid region resulting in colonic perforation and concurrent acute appendicitis is presented. During clinical evaluation, there were no signs of generalized peritonitis; abdominal sonography was performed to evaluate for acute appendicitis. An erect abdominal xray showed a radio opaque shadow in the right iliac fossa. At laparotomy, the tip of a pen was seen to perforate the sigmoid colon and impinge on the base of the appendix which was grossly inflamed. Subsequently, the pen was removed from within the colon and the colon was repaired in two layers. An appendicectomy was performed.
\end{abstract}

\section{Introduction}

Foreign bodies in the rectum cause complications and present a challenge to clinical management. They should be treated expeditiously.

\section{Case report}

A 9-year-old male child presented with complaints of pain in the right iliac fossa and anorexia for three days. On clinical examination, he was hemodynamically stable and afebrile, with marked tenderness in the right iliac fossa and rebound tenderness. Rectal examination was unremarakable. There were no signs of generalized peritonitis. Laboratory investigations revealed a total leukocyte count of $11,900 / \mathrm{cu} \mathrm{mm}$ with $80 \%$ polymorphonucleocytosis. Abdominal ultrasonography seemed to support the diagnosis of acute appendicitis.

Correspondence: T.A. Mala

E-mail: drtariq_6481mala@rediffmail.com
Furthermore, an erect abdominal x-ray showed a radio opaque shadow in the right iliac fossa [Figure 1]. There was no free air. A clinical diagnosis of acute appendicitis was made and patient was scheduled for appendicectomy - the presence of a colonic foreign body was not suspected.

During exploration of the abdomen through a Lanz incision, we found the tip of a pen to be present at the incision and formal laparotomy was performed by elongating the incision. The pen was seen perforating the rectosigmoid colon and touching the base of the appendix which was grossly inflamed [Figure 2]. The perforation, which was sealed by the pen, was one $\mathrm{cm}$ in length, and did not leak faecal content. The pen was carefully removed from the site of perforation which was repaired in two layers. The remainder of the bowel was inspected to look for any other perforation. The appendix, which was found to be grossly inflamed, was excised and submitted for histopathological examination. The abdomen was closed in layers.

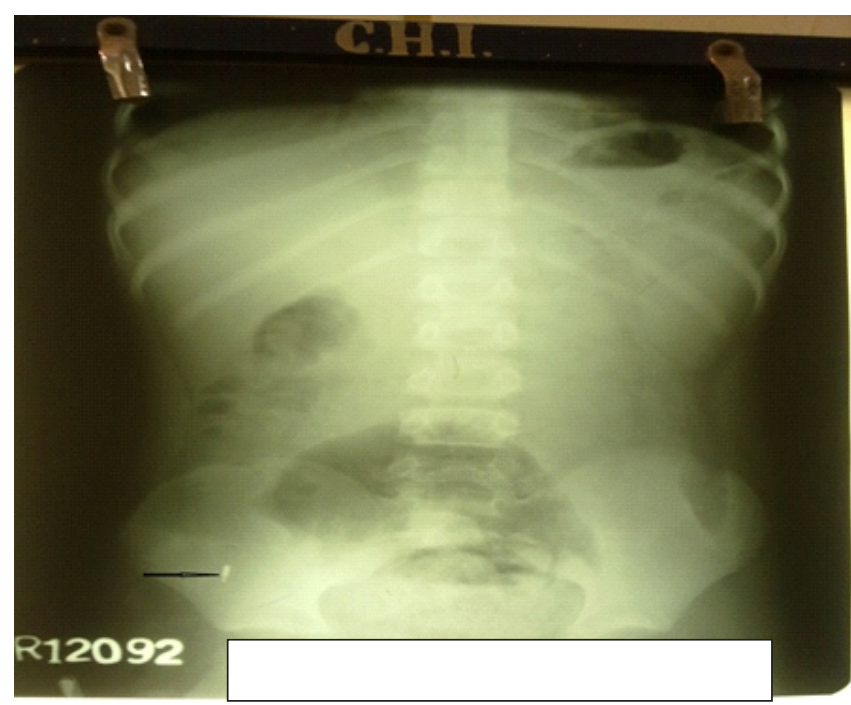

Figure 1. showing radio opaque shadow in the right iliac fossa 


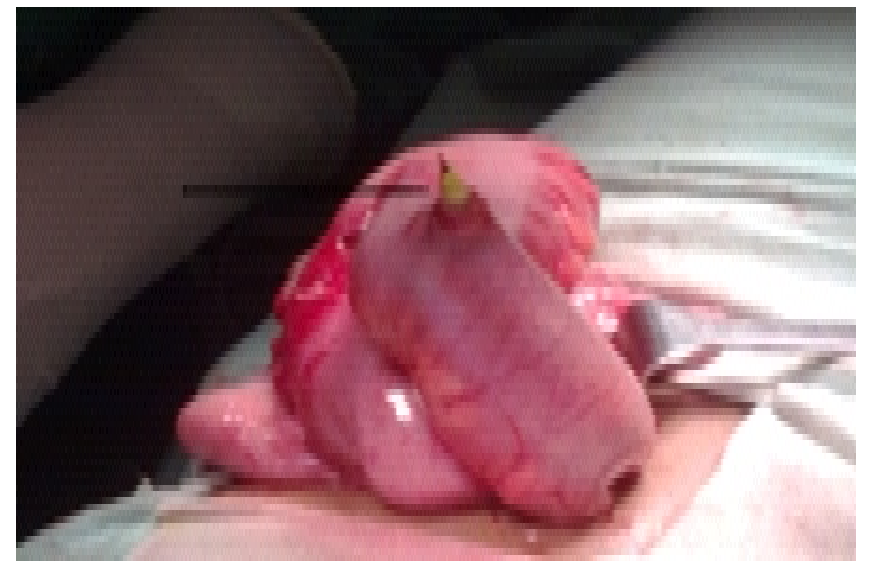

Figure 2. The tip of a pen seen perforating the sigmoid colon.

Postoperative recovery in this patient was uneventful. On further enquiry, the patient denied either swallowing or anal introduction of the pen. Histopathological report of appendectomy specimen confirmed acute appendicitis [Figure 3]. He was subsequently referred for psychometric assessment.

\section{Discussion}

The majority of reports of foreign bodies within the rectum are from the West [1-8], varying in age from 16 to 80 years [1]. There is a bimodal age distribution, observed in the twenties for anal erotism or forced introduction through anus, and in the elderly, mainly for prostatic massage or disimpaction of faeces. Reports have been more common in males compared with females [1.2]. Our case involved a 9-year old boy and is unusual. In general, an object is inserted into the rectum by the patient or partner for sexual gratification which may not be retrievable. Abdominal and rectal pain, rectal bleeding and urinary symptoms are the common presenting symptoms. In our case, complaints were pain in the right iliac fossa along with anorexia reflecting on acute appendicitis.

Impacted rectal foreign bodies commonly reported were plastic or glass bottles, vegetables, such as, cucumber and carrot, wooden and rubber objects [2]. In our case the foreign body was a ballpoint pen about $15 \mathrm{cms}$ in length. Richter also reported ballpoint pen rectal impaction in his study [8]. Although the abdominal xray revealed a radio-opaque shadow in the right lower quadrant of the abdomen, our attention was diverted by the clinical status of acute appendicitis, completely missing the thought of a possible foreign body impaction. A majority (90\%) of cases without perforation are treated by transanal retrieval of the foreign body $[1,2,6,7]$. Laparotomy is only required where a foreign body cannot be retrieved by conventional trans-anal methods and in the case of perforation. To the best of our knowledge, there has not been a report of acute appendicitis, proven by histological examination, with a concurrent foreign body penetration of the rectosigmoid colon in the world literature.

\section{References}

1. Biriukov IuV, Valkov OV, An VK, Elu B, Dodina AN. Treatment of patients with foreign body rectum (Russian) Khirurgiia. 2000;7:41-3. [PubMed]

2. Subbotin VM, Davidov MI, Abdrashitov RR, Rylov IuL, Sholin NV. Foreign bodies in rectum. Vestn Khir Im I I Grek. 2000;159:91-5. [PubMed]

3. Gaponov VV, Foreign bodies in the rectum and colon (Russian) Klinicheskaia Khirugiia. 1992;2:37-40.

4. Neprasova P, Treska V, Simanek V. Injury of rectum with porcelain cup (Czech) Rozhledy V Chirurgii. 2001;80:128-30. [PubMed]

5. Batho G, Szanto L. Foreign bodies in rectum at our department during last ten years. (Hungarian) Magyar Sebeszet. 2000;53:180-2. [PubMed]

6. Petrolito E, Bracchitta S, Calabrese C, Riolo G, Donati A, Pecorella G. Foreign bodies and injuries of the rectum (Italian) Minerva Chirurgica. 1989;44:867-71. [PubMed]

7. Kouraklis G, Miaiakos E, Dovas N, Karatzas G, Gogas J. Management of foreign bodies of the rectum: Report of 21 cases. J R Coll Edin. 1997;42:246-7.

8. Richter RM, Littman L. Endoscopic extraction of an unusual colonic foreign body. Gastrointest Endosc 1975; 22: 40

\section{Key points:}

- Presentation of acute appendicitis with a foreign body perforation, a rare occurence by a foreign body. 